\title{
A model for the allocation and utilisation of academic staff resources
}

\author{
STEPHEN GRIEW*
}

\begin{abstract}
It is argued that since an institution's recurrent income is so critically dependent on its total full-time equivalent enrolment, resource allocation should be based on measures of the contributions of individual teaching units to the institution's total full-time enrolment. A model is presented that permits the estimation of such contributions. The parameters generated by this model provide a basis for judgements concerning the efficiency of academic staff utilisation, the equitable deployment of staff in matrix organisations, the utilisation of staff in complex settings such as the professional school, and the assessment of spare, re-allocable teaching capacity. It is argued that the model assists an institution in facing up to the constraints imposed by its staff utilisation policies and, further, that it generates information of a kind that facilitates rational planning and decision-making in the allocation and utilisation of scarce teaching resources.
\end{abstract}

\section{RÉSUMÉ}

Il est argumenté que puisque le revenu périodique d'une institution dépend d'une façon tellement critique de son embauchage total équivalent à plein-temps, la répartition des ressources devrait ètre basée sur la mesure des contributions des groupes pédagogiques individuels à l'embauchage total à plein-temps de l'institution. Le modèle présenté permet l'estimation de telles contributions. Les paramètres engendrés par ce modèle fournissent une base pour les jugements concernant l'éfficacité de l'utilisation du personnel académique, le déploiement équitable du personnel en organisations matricielles, l'utilisation du personnel dans les cadres complexes tels que l'école professionelle, et l'évaluation de la possibilité éducative de résèrve et redistribuable. Il est argumenté que le modèle prête assistance à une institution en faisant face aux constraintes imposées par ses politiques d'emploi du personnel et, en outre, qu'il engendre des renseignements d'un type qui facilite une organisation rationelle et la prise de décisions dans la distribution et l'utilisation de ressources éducatives rares.

\footnotetext{
* Chairman, Department of Behavioural Science, Faculty of Medicine, University of Toronto; and President-designate, Athabasca University.
} 
The purposes of this note are, firstly, to propose a model for the allocation and utilisation of academic staff resources in universities and colleges, and, secondly, to enter a plea that the logic that underlies the model should be more realistically observed in resource deployment than ordinarily seems to be the case.

Decisions about the allocation and utilisation of academic staff resources are usually based upon assumptions concerning staff-student ratios appropriate to each of the various teaching activities in which the institution is engaged, staff teaching loads appropriate to each of these activities, or both. These assumptions may be either explicit or implicit, and are open, of course, to a great deal of argument and negotiation. The case of the institution that rigorously applies prescribed staff-student ratios to its constituent teaching units is rare, but the parameter is powerful in its capacity to allow comparisons between staffing levels in disparate teaching units and in exposing anomalies in staff deployment within an institution. Further, employed in conjunction with agreed norms for staff teaching load, it generates a series of constraints to which no institution can be indifferent in deciding the nature and extent of the teaching that it can offer.

\section{A currency for use in resource deployment}

It is proposed that the only currency that it is sensible for an individual institution to employ in making decisions about the deployment of its academic staff resources is that used by government granting agencies in establishing the recurrent grants to be made available to the institution. In one way or another this is ultimately some measure of the institution's full-time equivalent student enrolment. ${ }^{1}$ Others have been suggested and, indeed, used, of course, among them such measures as teaching load carried by an individual teaching unit, the actual number of students handled by an individual teaching unit, and so on. All of these, however, carry certain inherent disadvantages. Loads on individual departments can too easily be inflated by the proliferation of teaching dictated by the preferred teaching methods of their members. Raw enrolment figures can be insensitive indicators of load in that in one set of cases they may reflect the students' entire study programmes, while in another only a small proportion of their total programmes. In the latter case, of course, the use of raw enrolment figures will lead to multiple counting. In the final analysis, individual estimates of loads carried by teaching units must add up to the institution's actual, total full-time equivalent enrolment. If individual loads carried by its constituent units are not expressed in similar terms they will not accurately convey the extent to which they contribute to the institution's overall load, and thus their value in attracting the revenue which, when all is said and done, buys the staff who teach the institution's students.

\section{The model}

The logic underlying the model, therefore, is as follows.

The effort involved in teaching a group of students is not necessarily related to the value of those students in attracting financial resources to the institution. Each actual enrolment in a course or other teaching activity will contribute towards a full-time equivalent enrolment in a manner that is strictly calculable, depending upon the propor- 
tion of the student's full-time programme of study that is represented by the course or activity in question.

Further, in assessing the full-time equivalent enrolment handled by separate teaching units, the same actual enrolment cannot be credited equally to these separate units.

If departments A and B share the teaching of a course equally, then each may be credited with half its full-time equivalent enrolment.

And this leads to the final element in the logic. Full-time equivalent enrolments cannot be increased simply because logistic necessity or preferred teaching method dictates as unusual amount of contact with students enrolled in a course. Whether these students receive ten or only two hours of instruction a week, their value in attracting income to the institution will depend on the full-time equivalent enrolment that they generate.

Let $e_{i}$ be the full-time equivalent enrolment in course or activity $I$;

$n_{i}$ be the actual number of students enrolled in course or activity $I$;

$p_{i}$ be the proportion of a student's full-time annual programme of study represented by course or activity $I$;

Then $e_{i}=n_{i} p_{i}$

If $\quad \mathrm{H}_{\mathrm{i}}$ is taken to represent the total number of hours of formal teaching that is generated by course or activity I;

and $\quad h_{i(a)}, h_{i(b)}$ and $h_{i(c)}$ represent the numbers of hours contributed towards this teaching by departments $\mathrm{A}, \mathrm{B}$ and $\mathrm{C}$, respectively, so that $\mathrm{H}_{\mathrm{i}}=\mathrm{h}_{\mathrm{i}(\mathrm{a})}+\mathrm{h}_{\mathrm{i}(\mathrm{b})}+\mathrm{h}_{\mathrm{i}(\mathrm{c})}$,

then if $e_{i(a)}, e_{i(b)}$ and $e_{i(c)}$ are taken to represent, respectively, the full-time equivalent enrolments in course or activity $I$ handled by the teaching contributions of departments $\mathrm{A}, \mathrm{B}$ and $\mathrm{C}$,

$$
\begin{aligned}
& e_{i(a)}=e_{i} \frac{h_{i(a)}}{H_{i}} \\
& e_{i(b)}=e_{i} \frac{h_{i(b)}}{H_{i}} \\
& e_{i(c)}=e_{i} \frac{h_{i(c)}}{H_{i}}
\end{aligned}
$$

As an illustration, take the fictitious example of course BIO 345, an upper level undergraduate course taught jointly by the departments of zoology (Z), botany (B) and microbiology (M). It attracts an enrolment of 50 students, is a full-year course and one of four required by the annual programme of study of the students for which it is provided. It consists of 30 lectures each of two hours duration, 15 of which are given by members of the department of zoology, five by members of the department of botany, and 10 by members of the department of microbiology. There are also 30 laboratory 
sessions, each of three hours duration, and each supervised by two members of the zoology department, one member of the botany department, and one member of the department of microbiology.

In this case, $n_{i}=50, p_{i}=0.25$, and so it follows that $\mathrm{e}_{\mathrm{i}}=12.50 . \mathrm{H}_{\mathrm{i}}=420$, with contributions from the three contributing departments being as follows:

$$
\begin{aligned}
& h_{i(z)}=30+2(90)=210 \\
& h_{i(b)}=10+90=100 \\
& h_{i(m)}=20+90=110
\end{aligned}
$$

Thus,

$$
\begin{aligned}
& e_{i(z)}=12.50 \frac{210}{420}=6.25 \\
& e_{i(b)}=12.50 \frac{100}{420}=2.98 \\
& e_{i(m)}=12.50 \frac{110}{420}=3.27
\end{aligned}
$$

Faced with the need to provide 15 two-hour lectures to a class of 50 students, together with two instructors for weekly laboratory classes lasting three hours and again involving 50 students, many department chairmen would resist the conclusion that this course is worth only 6.25 full-time equivalent enrolments to his or her department, but the logic is inescapable.

This is a straight-forward case. More complex ones can be handled, however, so long as the underlying assumptions are agreed and applied consistently. It is essential in every case, of course, that $e_{i(a)}+e_{i(b)}+e_{i(c)} \ldots \ldots$ should add up to no more and no less than $e_{i}$; and that throughout the institution, individual values of $e_{i}$ should together add up to no more and no less than its actual full-time equivalent enrolment.

\section{Applying the model in the analysis of the teaching of an individual department}

In assessing an individual department's utilisation of its teaching resources it is necessary (1) to list all of its teaching activities, (2) to calculate values of $e_{i \text { (a) }}$ for these activities, and (3) to derive actual values of staff-student ratios and staff teaching loads that obtain for comparison with each other and with a range of possibly appropriate norms. Table 1 tabulates the teaching activities of a hypothetical department (A) during the academic session 1979-80. It is, again, a purposely very simplified case constructed simply in order to illustrate the method.

Department A consists of 17 full-time teaching staff of whom one, its chairman, is rated as $50 \%$ an administrator and thus only 0.50 a full-time equivalent teacher. In addition, this department has 11 part-time teaching members (mainly cross-appointed from other departments with which their salaries are shared) who, between them, add to its teaching strength to the extent of an additional 3.50 full-time equivalent teachers. 
77 A Model for the Allocation and Utilisation of Academic Staff Resources

Table 1. The teaching activities of Department A during 1979-80

\begin{tabular}{|c|c|c|c|c|c|c|c|}
\hline Activity & $n_{i}$ & $p_{i}$ & $e_{i}$ & $\mathrm{H}_{i}$ & $h_{i(a)}$ & $e_{i(a)}$ & $\frac{h_{i(a)}}{e_{i(a)}}$ \\
\hline A 101 & 200 & 0.25 & 50.00 & 660 & 660 & 50.00 & 13.20 \\
\hline A 102 & 100 & 0.25 & 25.00 & 300 & 300 & 25.00 & 12.00 \\
\hline A 103 * & 100 & 0.25 & 25.00 & 300 & 240 & 20.00 & 12.00 \\
\hline A 104 * & 50 & 0.25 & 12.50 & 180 & 120 & 8.33 & 14.41 \\
\hline A 105 * & 50 & 0.25 & 12.50 & 210 & 150 & 8.93 & 16.80 \\
\hline A 211 & 100 & 0.25 & 25.00 & 360 & 360 & 25.00 & 14.40 \\
\hline A 212 & 50 & 0.25 & 12.50 & 240 & 240 & 12.50 & 19.20 \\
\hline A 213 * & 60 & 0.25 & 15.00 & 420 & 210 & 7.50 & 28.00 \\
\hline A 223 & 20 & 0.25 & 5.00 & 120 & 120 & 5.00 & 24.00 \\
\hline A 224 & 10 & 0.50 & 5.00 & 60 & 60 & 5.00 & 12.00 \\
\hline A 351 * & 30 & 0.25 & 7.50 & 150 & 90 & 4.50 & 20.00 \\
\hline A 352 & 10 & 0.25 & 2.50 & 150 & 150 & 2.50 & 60.00 \\
\hline A 358 & 8 & 0.25 & 2.00 & 90 & 90 & 2.00 & 45.00 \\
\hline A 381 * & 4 & 0.25 & 1.00 & 180 & 150 & 0.83 & 180.72 \\
\hline A 401 * & 6 & 0.25 & 1.50 & 180 & 120 & 1.00 & 120.00 \\
\hline A 411 & 4 & 0.25 & 1.00 & 90 & 90 & 1.00 & 90.00 \\
\hline A 423 & 3 & 0.50 & 1.50 & 60 & 60 & 1.50 & 40.00 \\
\hline A 424 & 2 & 0.50 & 1.00 & 60 & 60 & 1.00 & 60.00 \\
\hline A 511 & 2 & 0.50 & 1.00 & 30 & 30 & 1.00 & 30.00 \\
\hline A 512 & 2 & 1.00 & 2.00 & 30 & 30 & 2.00 & 15.00 \\
\hline A 513 & 2 & 0.25 & 0.50 & 30 & 30 & 0.50 & 60.00 \\
\hline X $231 *$ & 72 & 0.25 & 18.00 & 120 & 20 & 3.00 & 6.67 \\
\hline Y 112 * & 314 & 0.25 & 78.50 & 500 & 20 & 3.14 & 6.37 \\
\hline
\end{tabular}

Note: Activities marked with an asterisk are those with which

Department A shares the teaching with other departments.

Since its total load in full-time equivalent student enrolments (the $\Sigma \mathrm{e}_{\mathrm{i}(\mathrm{a})}$ in Table 1) is 190.93 , its effective academic staff-student ratio in the year in question is 1:9.55. Further, since its total contact with students is 3,400 hours (the $\Sigma h_{i(a)}$ in Table 1), the annual contact per full-time equivalent staff member is 170 hours, or, based on an actual 28 week teaching year, 6.07 hours per week.

Purely in order to illustrate further the kinds of uses to which these data may be put, let us assume that other departments with teaching duties similar to those of department 
A enjoy staff-student ratios of approximately $1: 12$, and require their teaching staff to maintain contact with students for an average of nine hours per teaching week. If these norms are applied to department $A$, it could be argued that in the year in question that department should have contributed 5,040 hours of formal teaching to a total of 240 full-time equivalent students. In terms of formal teaching contact, therefore, it appears in $1979-80$ to be operating at $5,040-3,400$, or $32.5 \%$ below its capacity. In terms of full5,040

time equivalent enrolments, it appears to be operating at $240-190.93$, or $20.45 \%$ below its capacity.

240

If it is assumed that an appropriate staff-student ratio for such a department is $1: 12$, but that an appropriate weekly teaching load for its members is, in fact, six hours, then the conclusions will be different. It could then be argued that while it appears to be contributing an appropriate amount of teaching overall, its operation, in terms of its full-time equivalent enrolment, is at $20.45 \%$ below capacity, suggesting a not insignificant amount of "over-teaching" which could probably be corrected by revising its programme so as to contribute the same amount of teaching to larger classes designed to increase the value of $\Sigma \mathrm{e}_{\mathrm{i}(\mathrm{a})}$. Inspection of the column headed $\mathrm{h}_{\mathrm{i}(\mathrm{a})}$ in the table of teaching activities $\mathrm{e}_{\mathrm{i}}$ (a)

helps in the isolation of activities contributing particularly to the overall anomalies than are identified.

\section{Extensions of the model to handle more complex cases}

This was purposely a very simple example. More complex ones can be accommodated by the model, as the examples that follow demonstrate.

\section{Matrix organisation:}

The growth of multi-disciplinary programmes frequently leads nowadays to the vesting with one group of individuals the academic responsibility for teaching courses, while the allocation of teaching resources remains the responsibility of another group. A common difficulty that then arises relates to problem of deciding on an equitable distribution of teaching resources from participating administrative units to service the activities that are the responsibility of the programme coordinators.

Let us assume that Programme $R$ attracts an enrolment of $n_{r}$ students who plan to major in it. The programme demands that during their first year of study in this programme, these students must pursue a total of five courses, three of which must be core courses offered specifically to service Programme $R$,-and two selected from electives offered principally to service studies in other programmes. Further years of study can be handled similarly, but to simplify presentation we shall limit our discussion to one year of study.

Also to simplify presentation, let us assume that three of the courses designed specifically to service Programme $R$ each attracts an enrolment of $n_{0}$ students majoring in other programmes, and that each of these students are required by their programme regulations to pursue a total of five courses during the year in question.

Full-time equivalent enrolment in the component courses of Programme $\mathrm{R}$ can thus be calculated as follows: 
Full-time equivalent enrolments attributable to students enrolled as majors in Programme $R=n_{r} \frac{3}{5}$;

Full-time equivalent enrolments attributable to students enrolled as majors in other programmes $=3 n_{0} \frac{1}{5}$.

If we further assume that the courses offered specifically to service Programme $R$ have to be taught by members of departments $D, E$ and $F$ in equal proportion, and that a staffstudent ratio of $1: \mathrm{S}$ is established as appropriate for teaching of the kind that is involved, then the resources, in terms of equivalent full-time academic staff that should be allocated by each of the contributing departments to Programme $\mathrm{R}$ becomes: ${ }^{2}$

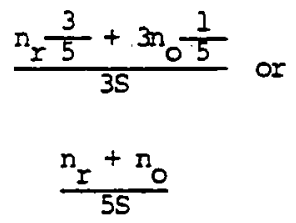

If norms for staff-student ratios appropriate to the teaching involved have not been established, then estimates can be based upon the actual ratios that apply in the departments concerned, arrived at by applying the method to analyses of their total teaching activities.

It would not be appropriate in a note of this kind to pursue the question in any detail, but it may be appropriate to comment that pleas often made by teaching staff with primary responsibility for such programmes as Programme $R$, that they should be allocated budgets of their own, are more often than not incompatible with usual (and many would claim the most desirable) administrative structures of universities and colleges. Responsibility for resource deployment at the programme level is ordinarily to be regarded as impractical unless the programme has achieved a size and stability that justifies its own, specially appointed faculty, at which time, of course, it assumes the character of a department or school. Until such a time, analyses along the lines of that which has just been presented go a long way towards ensuring an equitable deployment of teaching resources within multi-disciplinary programmes that must be serviced by a range of separate administrative units.

\section{The case of the professional school:}

Here it is sometimes difficult to fathom a method of identifying component teaching activities, of separating the contributions of constituent teaching units, and of placing a value on the full-time equivalence of a large number of part-time, and often honorary teaching staff. Again, however, the logic underlying the model can be mobilised in accommodating such complex cases.

For a start, the logic demands that honorary staff who receive no payment for their services should be discounted in assessing a unit's full-time equivalent teaching strength. If, in return for their involvement, the institution makes payment in kind then it makes sense to assess this in terms of the equivalent full-time staff that could be hired for the sums involved, and to count this in one's estimate of full-time equivalent staff within a 
unit. Part-time staff who are reimbursed on a sessional or, indeed, notional basis can be accommodated simply by calculating, again, the full-time equivalent staff that could be hired for the total fees that are involved. In doing so, of course, a cash value has to be established that realistically reflects the cost of hiring a full-time staff member in the area concerned, so that part-time fees can be equated with the proportion of a full-time equivalent teacher. This cash value will be the subject of local argument and negotiation, but under prevailing circumstances of severe financial restraint, it makes sense to set this value at a low rather than at a high level. If the eminent physicians or engineers or architects or lawyers who help teach our professional students of medicine, engineering, law and architecture were suddenly to withdraw their support, the fees they receive would most likely purchase only comparatively junior full-time faculty members, and this reality should be faced in assessing their contributions in terms of their full-time equivalence.

The identification of component teaching activities, yet again, may be pursued by reference to the logic underlying the model. A final year medical student, for instance, who, in addition to any formal courses he or she may attend, spends long hours in attendance at teaching hospitals working as a clinical clerk under the supervision of part-time teachers, can be treated in the following manner.

Assuming that his total programme credit for the year in question is distributed formally between formal courses and clinical instruction in the proportions $\mathrm{p}$ and $\mathrm{q}$, respectively, then the formal courses may be credited with a full-time equivalent enrolment in the case of this particular student of $1-q$, and the clinical instruction with the full-time equivalent enrolment of $1-p$. The credit attributable to each may be further distributed between contributing teaching units in proportion to the total amount of teaching in which they are involved in the case of this student. This is straight-forward in each case, but the logic demands that the long hours of supervision within the hospital setting should not be weighted to provide an inflated estimate of the full-time equivalent enrolment represented by this student. Assuming, to simplify presentation, that he spends a total of 14 hours a day, three days a week, for 48 weeks of the year in question working as a clinical clerk in internal medicine, surgery, obstetrics and gynaecology, and paediatrics, in equal proportions, then, despite the fact that these departments each supervise the student for a total of 504 hours, the student's value to each is no more and no less than $1-p$ full-time equivalent enrolment.

\section{Non-credit studies:}

A particularly compelling application of this model is to be found in the assessment of load in non-credit courses of the extra-mural and continuing education type, which generally generate no full-time equivalent enrolment credits, from which the institution only rarely derives grant income, but which results in an inescapable teaching load. Teaching staff will argue, not without justice, that where they are expected without additional remuneration to service such non-credit courses, the load so generated should be counted in assessing their total teaching load.

Since this load is not usually associated with full-time equivalent enrolment credit, the effect of regarding it as a part of total staff teaching load is to generate disparities between total teaching loads that actually obtain and those that may be calculated as appropriate 


\section{A Model for the Allocation and Utilisation of Academic Staff Resources}

on the basis of established norms for staff teaching contact. These disparities can be accommodated by appropriate institutional policies, but it is desirable that they should not be obscured. Inclusion of non-credit teaching should thus ideally be sought in analyses of departmental teaching, and should be associated with zero estimates of $e_{i(a)}$ in the appropriate table.

This becomes unnecessary, of course, if one's non-credit activities are handled on a selfsupporting basis, with student fees being set to cover costs, and participating staff being reimbursed for work that is then adjudged additional to regular teaching duties. A further refinement - though mainly one of theoretical interest - is to assess non-credit students as full-time equivalents in relation to the fees they generate. Thus, if an institution operates on the assumption that a regular student of the type concerned generates, if full-time, $\$ Z$, and a student attending this or that extra-mural course $\$ A$ in fees, then that student could be regarded as $Z$ of a full-time equivalent enrolment.

\section{$\overline{\mathrm{A}}$}

\section{The cost and value of different kinds of students}

It is customary in universities and colleges, implicitly if not explicitly, to regard certain categories of students as being more "valuable" or "costly" than others. The evidence comes in a variety of forms, the more obvious being our tendency to devote a good deal more time in the teaching of a full-time equivalent graduate or senior undergraduate student than in teaching a first year undergraduate equivalent, and our acknowledgement that more favourable staff-student ratios are required in schools of medicine and veterinary studies, than in Faculties of Arts. It is often suggested, when techniques of the kind now being proposed are discussed, that certain student enrolments should be weighted so as to recognise the differential values and costs of different categories of students.

This is a perfectly possible elaboration of the model. In fact it would have the merit of making explicit certain largely hidden assumptions that most commonly underly practice in resource allocation. However, the introduction of a weighting system will inevitably make one's individual values of $e_{i}$ add up to more than the institution's total actual fulltime equivalent enrolment. In consequence, all individual values will require scaling-down so as to bring this total back to its actual value. Any weighting system will thus require institution-wide adoption and application, as will any further weighting factors designed to bring individual values of $e_{i}$ back to levels that will ensure their summation to the institution's actual total full-time equivalent enrolment.

One way of handling this problem - and in terms of the logic of the model, possibly the most realistic - is to employ weights that reflect those employed by granting agencies in calculating the basic income to be awarded the institutions for which they are responsible. Since a medical student ordinarily attracts a higher basic grant to the institution than a student in the Arts Faculty, perhaps medical students should be weighted accordingly.

Weighting actual enrolments in calculating full-time equivalents, however, is associated with the obvious danger of giving double credit. Our assessments of the comparative values and costs of different kinds of students is most commonly reflected in the staff-student ratios we establish as appropriate to the activities of departments engaged in teaching students in different areas and at different levels. ${ }^{3}$ If we were to employ weights in assessing the full-time equivalent enrolments of different teaching units, it would cease being 
necessary to employ different staff-student ratios in establishing necessary or desirable staffing levels. To do so, in fact, would be to give double credit for increased value or cost.

\section{Part-time students}

Although this follows from much of the foregoing, it would be as well, perhaps, to make the point explicitly that students who are enrolled in the institution as part-time students will not be counted as full-time equivalents in the computation of its total enrolment. Different conventions apply in different settings, but the over-riding requirement is that each part-time student's contribution to the total full-time equivalent enrolment must be used as the basis of further calculations designed to assess his or her contribution to the full-time equivalent enrolment in each course or activity in which he or she is engaged.

\section{Further applications of the model}

\section{The assessment of spare teaching capacity:}

In times such as the present, when growth is restricted and funds scarce, an institution is often limited in its capacity to sponsor new developments, even though they may well serve to attract new populations of students who, in their turn, would result in increases of grant and fees income. In such circumstances, academic manoevrability becomes a particularly precious commodity, and planning strategies have to be sought that increase this manoevrability. Analyses of the kinds that have been presented are extremely powerful in identifying spare teaching capacity. This may be evidenced by an overall under-utilisation of teaching resources in a particular area, in terms either of its total teaching load, its handling of a requisite number of full-time equivalent enrolments appropriate to its level of staffing, or both. Further, the critical examination of individual teaching activities will identify some that are wasteful of resources, and some that involve the deployment of valuable resources in activities of only marginal essentiality in terms of the institution's overall goals and objectives.

Once identified, these examples of spare teaching capacity can be explored with a view to their possible re-allocation or re-deployment. Until they are identified, it is difficult even to begin exploring areas in which resources may be re-allocated or re-deployed.

\section{Facing the realities of constraints:}

An agreement that an institution's academic staff should be asked to engage in no more than, for example, nine hours teaching per week, in conjunction with the rude reality that financial constraints permit an overall staff-student ratio of $1: 15$, and a total, institutional full-time equivalent enrolment of 15,000 , leads by a process of simple arithmetic to the conclusion that the institution is capable of no more than 9,000 hours of teaching each week. Assuming, in order to simplfy the argument, that all courses in the institution involve four hours teaching contact each week, then the maximum number of courses that it will be able to offer will be 2,250 .

This logic is really inescapable. At the departmental level it is even more compelling. A full-time equivalent academic staff of 10 , each contracted to teach for a maximum of nine hours weekly, will provide a department with the capacity to offer a total of 90 hours of formal instruction each week. ${ }^{4}$ If it decides, despite institution convention, to invest six hours of contact in each of its courses rather than the four hours that is taken as the 
norm, then it will have either to teach only 15 rather than 22 or 23 courses, or accept voluntarily an individual staff teaching load of around $13 \frac{1}{2}$ hours per week.

Again, if it is decided at the institutional level to maintain a department of ten fulltime equivalent faculty, despite decreasing enrolments that serve to provide the department concerned with a staff-student ratio of $1: 4$, in contrast to an institutional average of $1: 12$, then it must simply be recognised that other units will be forced to accept staff-student ratios less favourable than $1: 12$. An institution may be forced to accept the maintenance of such departments on the grounds of compelling academic desirability, on frankly political grounds, or simply because all their faculty are tenured and thus not easily terminable. Unless means can be found to re-deploy certain of their members on other teaching activities, either staff-student ratios elsewhere in the institution will have to be reduced, or staff teaching loads increased, or the range of courses offered reduced. In some circumstances, more than one of these consequences will be inevitable.

\section{CONCLUSION}

Three final comments might be offered.

Firstly, the successful application of models such as this demands scrupulous candour from those whose responsibility it is to expose the details of their units' teaching activities. Experience suggests that this degree of candour will not readily be given unless undertakings are offered that no unit will be penalised insensitively for its willingness to be scrupulously honest about its activities. The measure of successful management in an institution will be its preparedness to work with and assist individual teaching units in their attempts to re-deploy their resources in manners that may be suggested by such analyses as these.

Secondly, in case it should be thought that the writer is indifferent to the needs of academic staff to devote time to their own scholarly and professional development, and to engage in research and professional activities unrelated to teaching, two points should be made explicit. In the first place, the reality in institutions supported principally by public funds and income from student fees is that their recurrent incomes are derived almost exclusively in proportion to the amount of teaching they declare themselves willing to offer to the full-time equivalent student enrolments they accept. The second point is the following. One of the critical parameters in any analysis of this kind is that representing a norm for the teaching load that it is reasonable to expect a faculty member to carry. This will be established with a view to the need to leave faculty members with enough time for research, professional development and, indeed, the routine adminisirative activities that have to be handled in the course of an institution's daily transaction of its affairs. This norm will be established as a result of discussion and negotiation within an institution. If it is set too high, academic staff (and ultimately students) will suffer. If it is set too low, the constraint that will follow on the range of teaching that the institution will be able to offer will reduce its viability, and again students (and ultimately staff) will suffer.

Finally, such techniques as that presented here often strike academics as being repugnant in that they appear to reduce scholarship to formula-generated income, and to pay greater heed to economic considerations than to the less tangible measures of need and achievement that are their customary preoccupations.

It should be emphasised that the purpose of such a model is essentially to expose a 
state-of-affairs in order to provide a rational basis upon which critical, and often painful decisions can be made. Strategic planning is now much more important than ever before, and this cannot proceed without reliable data. No decisions have to be made on the basis of the data so obtained from analyses such as these, but where they are made, they will be made on the basis of hard fact rather than insecure supposition. Further, they will require the exercise of judgement at a critical stage in the procedure. Where "inefficiency" is identified but no action taken to correct it, those concerned will at least know where it has been found to exist, what its cost is, and why nothing has been done about it. Institutional policies will, in the process, become significantly more refined and explicit.

\section{FOOTNOTES}

1. This assertion can be challenged, of course, in the case of the privately funded institution. Nonetheless, the proposition generates a logic that is equally applicable in both public and private institutions.

2. The principles underlying such thinking derives much from that underlying Program Budgeting (PPBS). The expression that follows could be employed as an element in the "cross-walk" budget proposed by J. Cutt in Program budgeting in higher education: a view of the state of the art. (Canberra; Australian National University Press, 1971).

3. It is not fortuitous, of course, that staff-student ratios tend to be most favourable in those areas traditionally recognised as requiring the most concentrated formal teaching, or that formula funding systems generally award the highest income units for enrolments in these areas.

4. The average formal teaching per full-time equivalent enrolment in a course is given by the expression $\underline{L}$ hours per week, where $\mathrm{L}=$ the average teaching load in hours per week that it is considered $\mathrm{E}$ appropriate for a staff member to carry, and $E=$ the denominator of the staff-student ratio considered appropriate to the teaching activity. Where a course or activity generates more teaching than this, it will have to be balanced by one that generates less if the average teaching load represented by the norm is to be preserved. 